\title{
Drug-drug Multi-component Crystal of Acedoben-Dimepranol 2:1
}

\author{
Tomomi Yoshida, ${ }^{*}$ Daiki Umeda, ${ }^{*}$ Okky Dwichandra Putra, ${ }^{* *}$ Hidehiro UeKuSA, ${ }^{* *}$ and \\ Etsuo YoNEMOCHI*† \\ *School of Pharmacy and Pharmaceutical Sciences, Hoshi University, 2-4-41 Ebara, Shinagawa, \\ Tokyo 142-8501, Japan \\ **Department of Chemistry and Materials Science, Tokyo Institute of Technology, 2-12-1 Ookayama, Meguro, \\ Tokyo 512-8551, Japan
}

\begin{abstract}
The structure of the drug-drug multi-component crystal of acedoben-dimepranol (2:1) was determined by single-crystal $\mathrm{X}$-ray crystallography. The compound crystallizes in a monoclinic system with space group $P 2_{1} / n$ resulting in the following unit cell: $a=7.78174(14) \AA, b=9.71395(18) \AA, c=63.5236(12) \AA, \beta=92.4271(7)^{\circ}, Z=4, V=4797.53(15) \AA^{3}$. The final values were $R_{1}=0.0443$ and $w R_{2}=0.1241$. Two acedoben molecules share a hydrogen atom between the $\mathrm{COOH}$ and $\mathrm{COO}-$ groups forming a mono cationic dimer unit. A counter charge is on $\mathrm{NH}^{+}$of the dimepranol molecule.
\end{abstract}

(Received March 24, 2016; Accepted June 30, 2016; Published on web September 10, 2016)

A multi-component crystal involves molecular assemblies consisting of drug substance(s) and a complementary molecule such as solvents or additives. ${ }^{1}$ One important subject concerning a multi-component crystal is a multi-drugs crystal. Drug-drug multi-component crystals have evoked a great interest in the pharmaceutical industry owing to better pharmacological profiles and technological advances. ${ }^{2}$ This class of materials can be considered to have potential relevance concerning context fixed-combination drugs as well as patent eligibility criteria, such as novelty, utility and non-obviousness for pharmaceutical development. ${ }^{3}$ Unfortunately, multi-drugs crystals are rarely explored. Herein, we report a new drug-drug multi-component crystal consisting of acedoben and dimepranol.

Acedoben (4-acetamidobenzoic acid) and dimepranol $(N, N-$ dimethylamino-2-propanol) are two of components in a triple drugs multi-component crystal of inosine pranobex. The drugs exerts modest antiviral activity as well as immune-stimulatory and immune-restorative activity. ${ }^{4-6}$ Although it is mentioned that acedoben and dimepranol form a salt crystal, to best of our knowledge, there is no clear evidence, such as spectroscopy and a crystallographic study concerning the occurrence of proton transfer for this multi-drugs crystal.

The title compound (Fig. 1) was isolated in our unsuccessful attempts to prepare a single crystal of inosine pranobex. Colorless-chunked crystals were obtained by slow evaporation from a methanol solution at room temperature.

The integrated and scaled data were empirically corrected for absorption effects with ABSCOR. ${ }^{7}$ The space group was determined by PLATON. ${ }^{8}$ The initial structures were solved by using a direct method with SHELXS-2014, ${ }^{9}$ and refined using a full-matrix least-squares method on $F^{2}$ using SHELXL-2014. ${ }^{10}$ The non-hydrogen atoms were refined anisotropically and the hydrogen atoms attached to the $\mathrm{N}$ and $\mathrm{O}$ atoms were found in a difference Fourier map and refined isotropically. All other hydrogen atoms were located geometrically and included in

$\dagger$ To whom correspondence should be addressed.

E-mail: e-yonemochi@hoshi.ac.jp least-squares calculations using the riding-atom model. Isotropic temperature factors constrained to $1.2 U_{\mathrm{eq}}(\mathrm{C}, \mathrm{O}, \mathrm{N})$ were given to all hydrogen atoms.

Crystallographic and experimental details are drawn in Table 1, and an ORTEP drawing of molecules in asymmetric unit is drawn in Fig. 2.

The asymmetric unit consists of two sets of independent molecules unit of acedoben:dimepranol $=2: 1$. In the difference Fourier map, a significant residual density peak is observed near to N1E and N1F of dimepranol molecules, which is assigned as a transferred hydrogen atom. Thus, we consider this multicomponent crystal to be a salt complex.

In the present study, we assigned $\mathrm{H} 1 \mathrm{C}$ to be shared by two carboxylic oxygen atoms of $\mathrm{O} 3 \mathrm{~B}$ and $\mathrm{O} 3 \mathrm{C}$, which is confirmed by the residual density of hydrogen atoms and its successful refinement. Also, the $\mathrm{C}-\mathrm{O}$ distances of related carboxylate groups that share the $\mathrm{H}$ atom are not equal, which indicate that they are not in the carboxylate state. Thus, we can bear a -0.5 charge by sharing the hydrogen atom. O3A $\cdots \mathrm{H} 2 \mathrm{C}-\mathrm{O} 3 \mathrm{D}$ is also recognized as another $\mathrm{H}$ atom sharing site in the same manner as that of to $\mathrm{O} 3 \mathrm{~B} \cdot \cdot \mathrm{H} 1 \mathrm{C}-\mathrm{O} 3 \mathrm{C}$.

As a result of proton sharing, strong $\mathrm{H}$ bonds between $\mathrm{O} 3 \mathrm{C}$ $\mathrm{O} 3 \mathrm{~B}$ and $\mathrm{O} 3 \mathrm{D}-\mathrm{O} 3 \mathrm{~A}$ are recognized (Table 2). The $\mathrm{O} \cdots \mathrm{O}$ distances of O3C-O3B and O3D-O3A are short enough and can be classified as strong hydrogen bonds. In such a hydrogen bond, the hydrogen atoms are often observed somewhere<smiles>CC(=O)Nc1ccc(C(=O)O)cc1</smiles>

Fig. 1 Chemical diagram of the title compound (acedoben (left) and dimepranol (right)). Each molecule is drawn as a neutral form. 
Table 1 Crystal and experimental data

Sum formula: $\mathrm{C}_{23} \mathrm{H}_{31} \mathrm{~N}_{3} \mathrm{O}_{7}$

Formula weight: 461.51

$T: 173(2) \mathrm{K}$

Crystal system: monoclinic Space group: $P 2_{1} / n$

$a=7.78174(14) \AA$

$b=9.71395(18) \AA$

$c=63.5236(12) \AA$

$\beta=92.4271(7)^{\circ}$

$V=4797.53(15) \AA^{3}$

$Z, Z^{\prime}=8,2$

$D_{\mathrm{x}}=1.278 \mathrm{~g} / \mathrm{cm}^{3}$

Radiation: $\mathrm{Cu} K_{\alpha}(\lambda=1.54186 \AA)$

$F\left(\begin{array}{lll}0 & 0 & 0\end{array}\right)=1968$

Crystal size $=0.227 \times 0.122 \times 0.100 \mathrm{~mm}^{3}$

No. of reflection collected $=38214$

No. of independent reflection $=8706$

No. of observations $(I>2 \sigma(I))=6778$

$\theta$ range for data collection: 4.180 to $68.235^{\circ}$

Data/Restrain $/$ Parameters $=8706 / 3 / 645$

$R$ indices $(I>2 \sigma(I)): R_{1}=0.0443, w R_{2}=0.1241$

$R$ indices (all data): $R_{1}=0.0565, w R_{2}=0.1319$

Largest diff. peak and hole: 0.594 and $-0.535 \mathrm{e}^{-3}$

Measurement: RIGAKU R-AXIS RAPID II

Structure determination: direct method (SHELXS-2014)

Refinement: full-matrix least squares (SHELXL-2014)

CCDC deposit number: 1470154

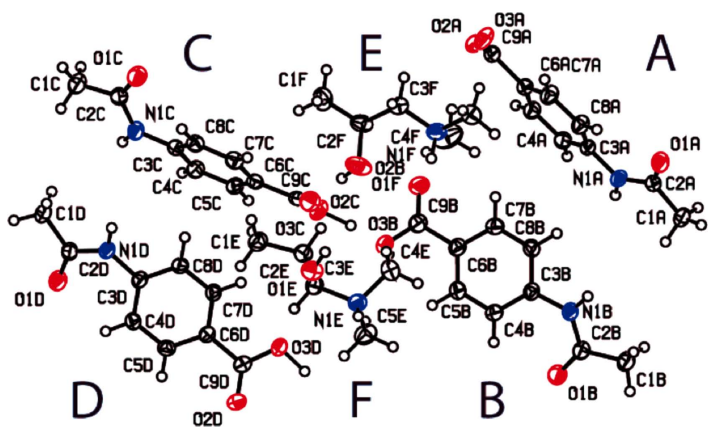

Fig. 2 ORTEP structure of title compound, showing $50 \%$ probability ellipsoids.

between the centers of two atoms rather than attaching to one oxygen atom. The structure reported, here is one such case.

All bond lengths, bond angles, dihedral angles and planarity appear to be not unusual in all fragments. In the acedoben molecules (fragment A, B, C and D), the carboxylic acid moieties are essentially co-planar with the benzene ring. A small deviation is observed in fragment $\mathrm{C}$ (dihedral angle $=$
Table 2 Selected hydrogen-bond geometry $\left(\AA,^{\circ}\right)$

\begin{tabular}{|c|c|c|c|c|}
\hline D-H...A & D-H & $\mathrm{H} \cdots \mathrm{A}$ & 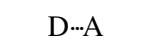 & $\mathrm{D}-\mathrm{H} \cdots \mathrm{A}$ \\
\hline $\mathrm{O} 3 \mathrm{C}-\mathrm{H} 1 \mathrm{C} \cdots \mathrm{O} 3 \mathrm{~B}$ & $1.18(2)$ & $1.29(2)$ & $2.4660(14)$ & $176(2)$ \\
\hline $\mathrm{O} 3 \mathrm{D}-\mathrm{H} 2 \mathrm{C} \cdots \mathrm{O} 3 \mathrm{~A}$ & $1.14(2)$ & $1.32(2)$ & $2.4499(13)$ & $170(2)$ \\
\hline
\end{tabular}

$\left.166.00(13)^{\circ}\right)$. The acetamide moieties are also not co-planar with respect to the benzene ring; the dihedral angles are $160.7(1)^{\circ}, 156.3(1)^{\circ}, 150.8(1)^{\circ}$ and $152.9(1)^{\circ}$ for fragments $\mathrm{A}$, $\mathrm{B}, \mathrm{C}$ and $\mathrm{D}$, respectively. As the result of protonation to dimepranol molecules, the $\mathrm{NH}^{+}$bond angles in $\mathrm{N} 1 \mathrm{E}$ and $\mathrm{N} 1 \mathrm{~F}$ are about $107^{\circ}$, since it has the tetrahedral geometry.

In conclusion, we have reported on the crystal structure of a salt complex consisting of a multi-drugs crystal of acedobendimepranol $=2: 1$. The hydrogen atom sharing site between two molecules of acedoben is recognized and the resulting strong hydrogen bond that occurs is few in crystallographic literature. This result is expected to provide fundamental information for designing triple-drugs multi-component crystal of inosine pranobex of which two of three constituents are reported here.

\section{Acknowledgements}

We acknowledge members of the focus group on Pharmaceutical Profiling of the Academy of Pharmaceutical Science and Technology (Japan) for valuable discussions.

\section{References}

1. G. P. Stahly, Cryst. Growth. Des., 2007, 7, 1007.

2. B. S. Sekhon, Daru., 2012, 20, 45.

3. N. Qiao, M. Li, W. Schlindwein, N. Malek, A. Davies, and G. Trappitt, Int. J. Pharm., 2011, 419, 1.

4. H. Onishi, K. Kosuzume, H. Inaba, M. Ohkura, S. Shimada, and Y. Suzuki, Int. J. Immunopharmacol., 1983, 5, 181.

5. H. Onzishi, K. Kosuzume, H. Inaba, M. Ohkura, Y. Morita, H. Mochizuki, and Y. Suzuki, Infect. Immun., 1982, 38, 243.

6. K. Y. Tsang, H. H. Fudenberg, and M. J. Gnagy, J. Clin. Invest., 1983, 71, 1750.

7. T. Higashi, 1995, ABSCOR, Empirical Absorption Correction Based on Fourier Series Approximation, Rigaku, Japan.

8. A. L. Spek, J. Appl. Cryst., 2003, 36, 7.

9. G. M. Sheldrick, 2014, SHELXS-2014, Program for Crystal Structure Analysis, University of Gottingen, Germany.

10. G. M. Sheldrick, 2014, SHELXL-2014, Program for Crystal Structure Refinement, University of Gottingen, Germany. 